\title{
Repetição como estratégia de dramaturgia em dança
}

\section{Resumo}

Juliana Moraes ${ }^{1}$

Neste artigo Juliana Moraes trata da repetição como maneira de alinhavar dramaturgia em dança uma estratégia que se tornou fundamental para seus trabalhos coreográficos nos últimos dez anos. A autora se debruça sobre estudos de Freud e alguns desenvolvimentos de Deleuze sobre a repetição, mais especificamente como ela opera na condução de narrativas inconscientes aparentemente descontínuas, para então traçar paralelos entre esta transação econômica psíquica e as dramaturgias de suas peças. Análises de obras do repertório Bauschiano também entram no discurso como exemplos de extenso uso da repetição como estratégia coreográfica.

Palavras-chave: Repetição; Dramaturgia; Dança Contemporânea; Coreografia.

\section{Abstract}

In this paper Juliana Moraes describes her use of repetition as a way to build dramaturgy in dance - a strategy that has become fundamental to her works in the last decade. Freud's studies about repetition and some developments brought by Deleuze are analyzed by the author, more specifically how repetition operates in the conduction of apparently discontinuous unconscious narratives, in order to then compare these psychical operations to the ones she develops in her pieces. Some of Pina Bausch's works are also analysed as examples of extensive use of repetition as a choreographic tool.

Key words: Repetition; Dramaturgy; Contemporary Dance; Choreography.

1.

Refletir sobre o uso da repetição como chave para construção dramatúrgica em dança me é fundamental, pois esta estratégia acabou por se sedimentar, nos últimos dez anos, como essencial em minhas criações. Se faço uso de meus conhecimentos em análise de Laban para criar um vocabulário de movimentos, faço o mesmo com relação ao uso da repetição para desenvolver as dramaturgias de minhas peças. Estes dois eixos, análise de Laban e repetição, tornaram-se constantes mesmo em meio a mudanças de tema e de interesses poéticos. Entretanto, procuro manter um foco aberto no sentido de explorar estas duas áreas de variadas maneiras, às vezes ques-

\footnotetext{
1 Juliana Moraes é doutora e bacharel em dança pela UNICAMP. Atua como professora do Centro Universitário Belas Artes de São Paulo e como diretora da Companhia Perdida.
} 
tionando-as em suas bases. São fontes de interesse flexíveis, e nunca formas enrijecidas por teorias prontas ou métodos.

O que me interessa com relação à repetição é como ela opera na construção de significados através de diferentes estratégias de organização do tempo e do espaço cênicos. Para tanto, a correlação com os estudos psicanalíticos, especialmente de Freud e subsequentemente alguns desenvolvimentos de Deleuze, são importantes, pois ambos refletem sobre como se dá a operação da repetição na organização da subjetividade em termos topográficos, temporais e econômicos. No caso, esta economia se refere a processos de elaboração que demandam deslocamentos de energia psíquica como, por exemplo, na passagem da condição passiva à condição ativa de um desprazer, ou na passagem da síntese passiva do tempo à síntese ativa - processos que descreveremos mais detidamente a seguir.

Não pude deixar de ver um paralelo entre essa economia psíquica na vida subjetiva, de transação espaço-temporal, e o trabalho do diretor/coreógrafo em cena. Phelan faz uma analogia entre a psicanálise e a dança por ambas se preocuparem em organizar o corpo (físico e subjetivo) no tempo.

A psicanálise é a performance na qual doutor e paciente interpretam um sintoma que dá ao corpo coerência temporal. Parte do fardo de estabelecer ordem temporal no corpo, tanto para a dança quanto para a psicanálise, frequentemente recai na narrativa, já que uma das coisas que a narrativa gera é ordem temporal. (PHELAN, 1997, pp. 55-56)2

O estudo das operações conscientes e inconscientes que Freud desenvolveu me são caros pois me possibilitam vislumbrar a criação do que denomino uma dramaturgia do in/consciente, que opera através de deslocamentos, condensações, repetições, substituições, trancos e loopings. Escrevo in/consciente para deixar claro que o processo se dá entre escolhas inconscientes e conscientes, e a transação define o espaço vivo e orgânico da criação, essa grafia topográfica e temporal que vou delineando durante todo o processo.

Dessa forma, a narrativa deixa de ser causal e também pode se eximir de depender das explicações didáticas de pantomimas, vídeos ou textos que muitas vezes são usados para levar peças de dança adiante. O inconsciente, como Freud demonstra habilmente, se faz notar através de estruturas que organizam sua massa

\footnotetext{
2 "Psychoanalysis is the performance in which the doctor and the patient interpret a symptom that gives the body temporal coherence. Part of the burden of establishing temporal order for the body, for both dancing and psychoanalysis, often falls to narrative since one of the things that narrative generates is temporal order."
} 
informe de formas profundamente não-causais, que desafiam nosso desejo programático. São essas operações e estratégias que me interessam, pois é nelas que vejo a energia psíquica funcionar coreograficamente através do deslocamento de imagens, acumulação de presentes em assemblages, pulsações que se aceleram ou desaceleram, jogos de esconde-esconde e assim por diante. Diferentemente de alguns que negligenciam as operações do inconsciente ironizando-o, como se fosse um homúnculo $^{3}$, minha visão é que suas formas sejam altamente libertárias, pois parto do pressuposto de que $o$ inconsciente se manifesta de forma fundamentalmente artística.

A relação entre repetição e narrativa em dança e a subsequente busca pela fortuna psicanalítica a esse respeito foram muito importantes nos estudos das obras de Pina Bausch, especialmente seus trabalhos das décadas de 70 e $80^{4}$. Bausch trouxe para o palco formas de elaboração espaço-temporais marcadas pela experiência da vida fora do palco, fazendo uso especialmente de operações assemelhadas às das repetições psíquicas traumáticas para alicerçar suas peças desse período. $\mathrm{A}$

3 Apesar de me interessar pelas ideias de Johnson e Lakoff a respeito das metáforas como conceitos fundamentados na experiência corporal, a completa negação que Johnson faz de aspectos inconscientes nas elaborações subjetivas no livro The Meaning of the Body me soam simplistas. Ademais, fazem-me questionar a própria ideia dos conceitos metafóricos que ele sustenta - afinal, apesar de não ter sido provado cientificamente pelas neurociências cognitivas, o termo inconsciente tornou-se corriqueiro em nossa experiência de mundo. Talvez ele mesmo seja, no fundo, um dos mais importantes conceitos metafóricos que fundamentam nossa vida - para o qual Freud deu especial atenção. Segundo Johnson: "The principal problem with James's account is his use of agency terms, such as 'selects', 'cuts', and 'carves'. Though James does not intend this, these terms suggest the need for a mental homunculus (a mini-conceptualizer in the 'mind') who does the selecting, cutting, and carving from experience. From the perspective of cognitive neurosciences, we know that there is no single neural ensemble, network, or system that conceptualizes, decides, chooses, or acts, and there is certainly no single locus of any faculty of thinking or willing." (JOHNSON, 1999, p. 89) ("O problema principal com a explicação de James é seu uso de termos agenciadores, como 'selecionar', 'cortar' e 'talhar'. Apesar de James não intencionar isso, estes termos sugerem a necessidade de um homúnculo mental (um mini conceitualizador na 'mente') que faz a seleção, o corte e o talhe da experiência. Da perspectiva das neurociências cognitivas, sabemos que não existe um conjunto neuronal singular, uma rede ou um sistema, que conceitualize, decida, escolha, ou aja, e que certamente não há um local singular para qualquer faculdade de pensamento e disposição.")

4 A repetição no trabalho de Pina Bausch foi estudada de forma muito detida pela professora e coreógrafa brasileira Ciane Fernandes, no livro Pina Bausch e o Wuppertal dança-teatro: repetição e transformação. Citemos dois trechos importantes: "Pela repetição, a agressão, inicialmente verbal, tornou-se carinho, e novamente agressão; é agora expressa pelo corpo, seu produtor e vítima silenciosa. Carinho e agressão não podem satisfazer o indivíduo, preso numa trama de relações sociais/gestuais. Uma persistente insatisfação subliminar impele os dançarinos a repetir carinho ou agressão, sozinhos ou com os parceiros. A cena contradiz a convenção de que dançarinos são seres completos, preenchidos pela total sensação e consciência física, e de que a dança é a presença de corpos no palco, já que estes são marcados pela ausência e pela insaciável necessidade do outro." (FERNANDES, 2000, p. 97). "Como as epidemias, os trabalhos de Bausch são intrinsecamente contraditórios: marcados pela repetição em eventos coletivos e ao mesmo tempo desafiando previsões e descrições prontas. Porém, por meio da repetição não encontram um ponto convergente e único, mas dissemina-se mais e mais." (Ibidem, p. 105) 
artista tornou-se mestra em poetizar experiências traumáticas em seu elemento mais basal: a impossibilidade do evento de simbolizar a si mesmo. ${ }^{5}$

Não é novidade o fato de Bausch ter encontrado essas estratégias poéticas a partir de uma maneira inovadora de criação, alicerçada em perguntas pessoais para seus intérpretes, que deveriam respondê-las poeticamente fazendo uso de variadas possibilidades como gestos, movimentos, falas, cantos, objetos, músicas etc. Ao trazer para o palco muito mais do que exclusivamente o movimento, Bausch possibilitou que os significados se complicassem exponencialmente.

Também não é novidade a especulação de que Bausch tenha levado para o palco operações que resistem à simbolização, fazendo muitas vezes uso da repetição em sua forma compulsiva, por conta de ter nascido na Alemanha em meio à Segunda Guerra e conhecer as angústias dela derivadas. Silverman argumenta que em momentos de traumas históricos, os pilares da ficção dominante são estremecidos (SILVERMAN, 2002). Pina Bausch começou a coreografar na época em que a Alemanha recuperava-se de sua destruição pela guerra e a grande tradição da dança-teatro estava praticamente esquecida. Ela recuperou essa tradição, porém suas peças expõem as ideologias que baseiam nossa sociedade como feridas coletivas que parecem não cicatrizar. Bausch mostra a maldade e indiferença do coletivo frente ao indivíduo, como se o palco fosse um terreno para comunicações fracassadas que levam frequentemente à violência de ordem íntima.

Procuro refletir sobre suas estratégias e compará-las às minhas, percebendo as diferenças e similaridades que se imbricam nessa comparação. Sempre senti uma forte resistência de minha parte a levar a repetição ao limite de seu aniquilamento, como Bausch faz, por considerar que esta estratégia seria, em primeiro lugar, uma cópia sem fundamento, mas especialmente por sentir que meu interesse se coloca nas operações de simbolização que a repetição proporciona. Se Bausch expõe eventos traumáticos que não conseguem simbolizar a si mesmos, desejo em meus trabalhos esticar o processo de construção de significados sem, no entanto, rompê-lo totalmente.

Em Bausch as cenas engolem a si mesmas, aniquilam-se e caminham para trás através da repetição compulsiva; já em meus trabalhos procuro sempre um movimento

\footnotetext{
5 "When I say trauma is untouchable, I mean that it cannot be represented. The symbolic cannot carry it: trauma makes a tear in the symbolic network itself." (Phelan, 1997, p. 5) ("Quando digo que trauma é intocável, quero dizer que ele não pode ser representado. O simbólico não pode carregá-lo: o trauma faz uma fissura na própria rede simbólica.")
} 
para frente, que resista a ser engolido por si mesmo. Nessa tensão, vou construindo as dramaturgias de minhas peças, oferecendo imagens, gestos, texturas/frequências e assemblages de movimentos, para então trançá-los ao longo da performance.

A ideia de assemblage vem de minha relação com as artes visuais, pois parte do princípio de que qualquer material pode ser incorporado numa obra para se inventar um novo conjunto sem que as partes se dissolvam completamente umas nas outras - é exatamente assim que crio muitas de minhas cenas, nessa "estética da acumulação"6. Ao desenhar temporal e espacialmente as cenas criadas ao longo do processo para levá-las ao palco num espetáculo, sinto que meu trabalho fica entre o da bordadeira e do editor de um filme.

\title{
2.
}

Por que repetimos? Peggy Phelan oferece uma interessante resposta: repetimos porque não conseguimos sustentar e porque não conseguimos conter.

\begin{abstract}
A promessa daquela sentença final constantemente adiada, da escrita exuberante feita no céu, do porquê da própria escrita, é o que nos mantém executando atos repetidos de visão, atos repetidos de amor. Devem ser repetidos porque não podem ser sustentados. A radical falta de forma e a aparente infinidade da nossa visão, da nossa sexualidade, da nossa morte, torna-lhes impossível se tornarem "still lives". A impossibilidade de declarar ou de decidir o que constitui nossos hábitos da visão, de fazer amor, de morrer, nos leva a nos ocuparmos em renomear e repetir nossas tentativas de conter estas coisas. (PHELAN, 1997, pp. 42-43) ${ }^{7}$
\end{abstract}

No livro Difference and repetition, Deleuze elabora dois conceitos importantes que se referem à nossa relação com o tempo: síntese passiva e síntese ativa. Ele denomina de síntese passiva nossa capacidade sensorial de contrair os muitos instantes de tempo para criar a sensação de presente. Segundo ele: "O tempo se constitui somente na síntese originária que opera na recepção de instantes. Essa síntese contrai os instantes sucessivos uns aos outros, constituindo assim o vivo, ou sendo vivido, presente"8 (DELEUZE, 1997a, p. 70). Como contraponto, o autor define como síntese

6 "Estética da acumulação": termo cunhado por Jean Dubuffet (1901 - 1985) para tratar de obras que vão além das colagens. Minhas maiores referências com relação à assemblage são as obras de Robert Rauschemberg.

7 "The promise of that constantly deferred final sentence, exuberant sky writing, why's own writing, is what keeps us performing repeated acts of looking, repeated acts of loving. They must be repeated because they cannot be sustained. The radical formlessness and apparent endlessness of our vision, of our sexuality, of our dying, makes it impossible to still these things and declare them "still lives". The impossibility of declaring or deciding what constitutes our habits of looking, of making love, of dying, leads us to occupy ourselves with re-naming and repeating our attempts to contain these things."

8 "Time is constituted only in the originary synthesis which operates on the repetition of instants. This synthesis 
ativa a operação de recolhimento de alguns instantes para guardá-los na memória. Se fôssemos incapazes de passar da percepção imediata para a memória, o tempo seria um sempre presente; é nossa habilidade de abrir dimensões no tempo que nos permite criar histórias. A síntese passiva seria imediata, enquanto a síntese ativa aliar-se-ia a processos de reflexão. Ao passar da síntese passiva para a ativa, a percepção de tempo se modifica profundamente pois:

O passado deixa de ser o passado imediato da retenção para se tornar o passado reflexivo da representação, ou particularidade refletida e reproduzida. Correlativamente, o futuro também deixa de ser o futuro imediato da antecipação para se tornar o futuro reflexivo da previsão. (Ibidem p. 71) ${ }^{9}$

Vejamos as ideias do autor esquematicamente:

$\begin{array}{ll}\text { síntese passiva } & \text { síntese ativa } \\ \text { tempo imediato } & \text { tempo refletido } \\ \text { antecipação (futuro) } & \text { previsão (futuro) } \\ \text { retenção (passado) } & \text { representação (passado) }\end{array}$

Numa sequência $A B, A B, A B, A B, \ldots$, toda vez que percebemos $A$, antecipamos $B$. Essa expectativa faz parte do tempo imediato da antecipação, ainda não enraizado no tempo refletido da previsão. Por exemplo, ao assistirmos a uma das muitas cenas de Pina Bausch que usam a expectativa derivada da repetição binária, como em Bluebeard (1977) as mulheres se arrastando no chão de folhas secas toda vez que a música toca, nós experimentamos uma sensação resultante de participarmos daquele momento. $A$ expectativa cria a sensação de participação justamente porque ela faz parte da forma como construímos a ilusão do presente. De outra forma: na expectativa, o passado ainda não se formou como memória e mesmo que o tempo cronológico passe por nós, a sensação ainda é de presente. Entretanto, depois de terminada a cena das mulheres se arrastando toda vez que a música toca, em suas reaparições, mais tarde no espetáculo, a vemos com outros olhos, ou seja, como aquilo que já passou e está sendo reapresentado. Consequentemente, na primeira vez em que a assistimos ela opera dentro da síntese passiva, e em suas reaparições ela opera dentro da síntese ativa.

Ao estudar a repetição como estratégia de construção narrativa em dança no meu mestrado no Laban Centre de Londres, em 2000, vi-me fazendo elaborações cria-

contracts the successive independent instants into one another, thereby constituting the lived, or living, experience." 9 "The past is then no longer the immediate past of retention but the reflexive past of representation, of reflected and reproduced particularity. Correlatively, the future also ceases to be the immediate future of anticipation in order to become the reflexive future of prediction." 
tivas que reverberavam minhas leituras. A primeira delas foi criar dentro do que denomino de texturas ou frequências qualitativas de movimentos, estudadas e praticadas exaustivamente em ensaios, mas que se mantém abertas para que o sequenciamento dos movimentos se dê somente no tempo-espaço da cena. A palavra textura vem de minha relação com as artes plásticas e a importância da qualidade dos materiais, e a palavra frequência vem de um pensamento sobre as ondas que compõem os sons. Há muitas pessoas que preferem a palavra "estado" para designar estruturas qualitativas associadas à performance do corpo, mas para mim as palavras textura e frequência contêm a qualidade de repetição que me interessa. Por exemplo, ao observar um material como uma trama feita de linhas, se ela se torna mais espessa em algum momento sua textura também muda. Em termos sonoros, qualquer mudança nas ondas modifica as frequências. Quando estou dançando, sinto meu corpo como um material que se modifica pelo calor, forças, direções, vetores etc., em mudanças que são de fato materiais e operam por texturas e frequências. Sendo assim, essas duas palavras me parecem ser mais específicas e menos gerais do que "estado".

Com essas texturas/frequências, minha intenção é que meu trabalho como intérprete opere dentro da síntese passiva, friccionando retenções, antecipações e expectativas, ao invés de entrar no universo da repetição de formas fixas desenvolvidas anteriormente nos ensaios. Ao explorar a textura que se faz ao vivo, no tempo presente da cena, meu corpo se mantém aberto, instável e exposto, ao invés de se sedimentar na forma.

Preferencialmente, a questão é produzir dentro do trabalho um movimento capaz de afetar a mente fora de toda a representação; a questão é fazer o próprio movimento trabalhar, sem interposição; é substituir representações mediadas por sinais diretos; é inventar vibrações, rotações, giros, gravitações, danças ou saltos que toquem diretamente a mente. (DELEUZE, 1997a, p. 8) $)^{10}$

Essas frequências ou texturas qualitativas se desenvolvem a partir de variadas fontes, e quando várias texturas/frequências se unem em partes diferentes do meu corpo dou o nome de assemblage. Por exemplo, no caso de minha peça de mestrado, Querida Sra.M., (2000-2002), criei uma cena a partir de poses femininas no ato sexual (esta cena foi incorporada em 3 tempos num quarto sem lembrança). Busquei posturas tanto em filmes e revistas pornográficos quanto em minha própria memória. Além

\footnotetext{
10 "Rather, it is a question of producing within the work a movement capable of affecting the mind outside all representation; it is a question of making movement itself at work, without interposition, of substituting direct signs for mediate representations; of inventing vibrations, rotations, whirlings, gravitations, dances or leaps which directly touch the mind."
} 
disso, estudei o quadro de Salvador Dali Phenomenon of ecstasy (1933), repleto de fotografias de mulheres histéricas, cujos olhos estão ou fechados ou nas diagonais do globo ocular. Assim, coreografei meus olhos colocando-os sempre de canto, nunca de frente. A partir da repetição nos ensaios, fui me tornando cada vez mais hábil em posicionar rapidamente meu corpo nessas posturas e transitar entre elas. Entretanto, nunca fixei uma sequência, ao contrário, sempre resisti a qualquer tentativa do meu corpo de adaptação a uma ordem previsível.

Depois de certa habilidade para transitar entre as posturas, adicionei mais um elemento complicador: a respiração extremamente forte, ritmada e audível, feita exclusivamente pelo nariz. Essa respiração faz com que o corpo se canse ainda mais e é necessária grande concentração, pois executo movimentos que demandam um tipo de respiração, mas realizo outra. As transições entre as posturas são feitas mecanicamente, sem adição de fluxos que pudessem suavizá-las. Quis separar o meu corpo em dois, sendo as posturas a da mulher no ato sexual e a respiração a de um homem que, durante o sexo, se mantém fixo em seu próprio padrão, não se permitindo mesclar com a mulher. Meu desejo era veicular, numa única ação, o automatismo de uma mulher passando por diferentes posturas sexuais e o automatismo de um homem no sexo através de sua respiração. Desta forma, a cena se alicerça em três pilares simultâneos: as posturas de sexo da mulher, os olhos no canto do globo ocular e a respiração forte somente pelo nariz. A junção de todas essas texturas/frequências no meu corpo é o que denomino de assemblage.

Nesta cena meu corpo funciona como um arquivo de computador, repleto de pastas com informações que acesso a partir do que seja possível no momento, pois o corpo determina as possibilidades de acordo com seus apoios, localizações espaciais e cansaço. No caso, criei a pasta corporal/mental para a cena de sexo e nela coloquei todas as posturas. Meu trabalho como intérprete e coreógrafa se dá ao escolher, no tempo mesmo da cena, quais informações/posturas aparecem a cada instante. Meu domínio é bastante irregular, pois o desafio é que as escolhas se deem antes do tempo da previsibilidade, tanto para o espectador quanto para mim mesma.

No solo Querida Sra. M.,, a cena de sexo é condicionada por um refletor lateral, de forma que toda vez que ele se acende eu devo interromper qualquer outra cena que estiver fazendo para retomar a frequência baseada em poses sexuais, num exemplo claro de repetição binária que passa da síntese passiva para a ativa. Quando a peça 
foi apresentada no Laban Centre de Londres, não pude dançar pois estava me recuperando de uma terrível caxumba e tive que terminar a criação com minha colega Marion Ramirez dançando em meu lugar. Sendo assim, no dia da apresentação fiquei na cabine de luz ligando e desligando o refletor para que a intérprete tivesse que segui-lo no palco. Acredito que estratégias que adicionam surpresa para o intérprete são fundamentais para se manter um estado presente e vivo em cena.

Meus trabalhos vêm se alicerçando em construir blocos de cenas que mais adiante posso retomar e opor, criando assim uma narrativa que se constitui na imbricação dos blocos inicialmente apresentados. Talvez o trabalho no qual melhor tenha conseguido elaborar a narrativa desta forma seja o solo 3 tempos num quarto sem lembrança (2005), que fiz ao reunir cenas de três trabalhos anteriores: Querida Sra. M., (2000-2002), Dois Sopros (2004) e Corpos Partidos (2005).

3 tempos num quarto sem lembrança tem uma primeira cena extremamente marcante, que fazia parte da peça Corpos Partidos: no início os espectadores me veem sentada sobre uma cama de solteiro de $5 \mathrm{~m}$ de comprimento, com os pés apoiados sobre um degrau (na primeira versão a cena acontecia numa escada). Depois de instaurada a tranquilidade pelo silêncio, de súbito inicio movimentos ritmados com a cabeça de um lado para o outro, os calcanhares também de um lado a outro mas em tempo diferente, enquanto simultaneamente executo gestos circulares e leves com os braços (às vezes pontuados com acelerações). Ao dividir o corpo em três segmentos, minha intenção é somar numa assemblage três frequências distintas que, através do treinamento, dão origem a uma soma extremamente clara, porém repleta de informações díspares. Opero, assim, da mesma forma que na cena de sexo do solo Querida Sra. M.,, ou seja, adiciono na mesma ação três momentos distintos e os forço a habitar o presente. Esta cena, especificamente, parece ter se impregnado nas mentes de muitas pessoas, que durante anos, e ainda hoje, mexem a cabeça de um lado para o outro assim que me veem, numa referência clara a essa imagem. A música para a cena, composta especialmente por Laércio Resende, segue caráter minimalista de séries melódicas sobre pulsações rítmicas que vão se diferenciando de si mesmas a cada nova repetição.

As posturas e os gestos saíram de fontes variadas: o gesto da cabeça é um "não" que se estende ao infinito, o movimento dos pés dá a marcação do ritmo da música e os gestos dos braços foram retirados do dia a dia. São jeitos de falar, apontar, nomear, esperar, ficar com raiva, mostrar descaso, contar, perguntar, conferir, etc. No 
meio de tudo isso, ainda introduzo imagens que retirei de revistas, nas quais são identificadas posturas notadamente femininas, veiculadas à exaustão pelos meios de comunicação. Pernas geralmente unidas nos joelhos para não deixar ver a genitália, ombros erguidos, biquinhos, quadris curvados, pés tocando o chão com os dedos e calcanhares elevados. Minha intenção é ativar um curto-circuito no corpo a partir da acumulação de todas essas informações.

Apesar de executada durante cinco minutos, a cena embaralha o tempo de percepção, e não são raras as pessoas que vêm me perguntar como consigo manter a performance durante tanto tempo e que ficam, de fato, confusas quando respondo que a cena dura cinco minutos. A força dessa primeira cena é fundamental para que toda a peça funcione, pois ela reaparece em determinados momentos, às vezes mais sutilmente, outras menos. Cada menção à primeira cena faz a narrativa retornar ao seu início, operando loopings e trancos no tempo.

Com respeito a esse poder, a repetição interioriza e assim reverte a si mesma: como Péguy diz, não é o Dia da Federação que comemora ou representa a queda da Bastilha, mas é a queda da Bastilha que celebra e repete adiantado todos os Dias da Federação. (DELEUZE, 1997a, p. 1) ${ }^{11}$

Meu desejo é que essa primeira cena seja minha queda da Bastilha.

3.

Como já foi dito anteriormente, a síntese ativa é desencadeada quando instantes que anteriormente pertenciam à percepção do presente são selecionados e passam a habitar a memória. A memória se constitui, assim, por um processo de seleção e transformação das experiências vividas em um passado de instantes escolhidos. "Memória é a síntese fundamental do tempo que constitui o ser do passado (aquilo que faz o presente passar)"12 (DELEUZE, 1997a, p. 80).

Como um dos exemplos mais marcantes de como uma imagem entra para a memória do espectador, podemos citar a famosa cena de Café Müller (1978) do casal cujo abraço é manipulado por um terceiro indivíduo repetidas vezes. Feita cada vez mais aceleradamente, o casal passa a repetir a manipulação mesmo sem o terceiro indivíduo - como autômatos que aprendem a se automoverem. Depois de assistirmos

\footnotetext{
11 "With respect to this power, repetition interiorizes and thereby reverses itself: as Péguy says, it is not Federation Day which commemorates or represents the fall of the Bastille, but the fall of the Bastille which celebrates and repeats in advance all the Federation Days."

12 "Memory is the fundamental synthesis of time which constitutes the being of the past (that which causes the present to pass."
} 
a esta cena, que brilhantemente estende o tempo na expectativa, os instantes percebidos são alojados na memória e, desta forma, podem servir como pedaços de informação para construir e desconstruir significados ao longo da peça. "Há toda razão para se acreditar que é no tempo, no silêncio e no corpo, que o signo se faça e desfaça"13 (PAVIS apud GARNER, 1994, p. 15).

Toda vez que o abraço do casal reaparece em Café Müller, mesmo que em meio a outras cenas, lembramos do momento em que presenciamos seu nascimento. $O$ abraço pode, então, ser feito no chão, pela metade, ou deixado como rascunho incompleto, pois mesmo assim nós o identificamos. A consciência de que a cena já apareceu antes é ativada pela lembrança que a própria coreógrafa nos concede com seus pequenos souvenirs - "a consciência surge no lugar do traço de lembrança" (FREUD, 2010, p. 186). A genialidade de Bausch é que ela escolhe aquilo que entra para a memória do espectador e depois pinça a lembrança quando lhe convém ao oferecer pequenos souvenirs da experiência inicial.

Mas se continuarmos com o exemplo de Pina Bausch, nas suas criações dos anos 70 e 80 , muitas vezes a repetição que cria uma expectativa na síntese passiva (ou antecipação) parece resistir a ser usada como alicerce para novas cenas: nada se constrói de realmente novo a partir da repetição. A repetição de Bausch se autodestrói pelo excesso; ela descola de si qualquer significado que possa ter dado a inferir. Novamente usando o abraço do casal de Café Müller como exemplo: apesar de ele reaparecer no chão ou em rascunho, ele não se transforma em outra coisa. Sendo assim, ao reaparecer somente em pequenas digressões, o abraço fica para sempre partido e cada recorrência o faz ainda mais solitário. Como Marcio Seligmann disse na palestra Repetição e Dramurgia, parte de um ciclo promovido pela Companhia Perdida em 2009: "As imagens traumáticas não conseguem simbolizar."14

Podemos traçar um paralelo entre esta estratégia narrativa de Bausch e a repetição compulsiva analisada por Freud, pois nesta forma de repetição a força de união não existe. $O$ indivíduo é incapaz de construir algo a partir do estímulo porque ele é incapaz de manter o estímulo no passado. Na repetição compulsiva a experiência permanece flutuando livremente, ela não se estabiliza para suportar outra coisa. A

\footnotetext{
13 "There is every reason to believe that it is in time, in silence and in the body, that the sign is made and unmade." 14 Palestra Repetição e Dramaturgia, com Márcio Seligmann e mediação de Cassiano Quilici. Parte do Ciclo de Palestras promovidos pela Companhia Perdida, $6^{\circ}$ Fomento à Dança da Cidade de São Paulo. Livraria da Vila, Rua Lorena, 10 dez. 2009.
} 
repetição compulsiva seria aquilo que não quer ser esquecido mas que também não quer ser "relembrado", ela quer ser revivida eternamente através da repetição. "Ele [o paciente] é antes levado a repetir o reprimido como vivência atual, em vez de, como preferiria o médico, recordá-lo como parte do passado" (FREUD, 2010, p. 177).

O desejo de dominar experiências desagradáveis é uma das explicações oferecidas por Freud para a repetição das mesmas pelo sujeito, que repete a experiência em formas dispersas para passar da posição passiva para a posição ativa em relação ao estímulo que causou o desprazer (como no famoso exemplo do jogo imaginário Fort $/ D a^{15}$, inventado pelo seu neto). Entretanto, ele reconhece que o desejo de domínio não engloba os casos nos quais o indivíduo exibe uma compulsão repetitiva. Haveria, portanto, duas formas distintas de repetição: a repetição na qual o sujeito adquire domínio sobre o desprazer (Fort/Da) operaria de acordo com o princípio do prazer, pois serviria para descarregar o excesso de excitação; já a compulsão repetitiva não operaria de acordo com o princípio do prazer, pois a excitação que ela provoca não diminui com o tempo.

As observações de Freud a respeito da repetição estão no cerne de seu famoso texto Para além do princípio do prazer, de 1920. Vejamos mais detidamente como ele desenha parte de sua teoria. Ele nota que quando a pessoa tem tempo para se preparar para um evento de profundo desprazer, a elaboração da perda acontece aos poucos, de antemão. Tomemos a liberdade de oferecer um exemplo da vida: pensemos num ente querido que morre depois de anos lutando contra o câncer. Quando ele morre, chegamos a pensar que foi melhor porque o sofrimento já não cabia mais. Entretanto, se o ente querido morre traumaticamente num acidente, a falta de preparação abre uma

\footnotetext{
15 "Esse bom menino tinha o hábito, ocasionalmente importuno, de jogar todos os pequenos objetos que alcançava para longe de si, a um canto do aposento, debaixo da cama etc., de modo que reunir os seus brinquedos não era coisa fácil. Ao fazer isso ele proferia, com expressão de interesse e satisfação, um forte e prolongado o-o-o-o, que, no julgamento da mãe e no deste observador, não era uma interjeição e significava "fort" ["foi embora"]. Afinal percebi que era um jogo e que o menino apenas usava todos os seus brinquedos para jogar "ir embora". Um dia pude fazer a observação que confirmou minha opinião. Ele tinha um carretel de madeira, em que estava enrolado um cordão. Nunca lhe ocorria, por exemplo, puxá-lo atrás de si pelo chão, brincar de carro com ele; em vez disso, com habilidade lançava o carretel, seguro pelo cordão, para dentro do berço, através de seu cortinado, de modo que ele desaparecia, nisso falando o significativo o-o-o-o, e depois o puxava novamente para fora do berço, saudando o aparecimento com uma alegre "da" ["está aqui"]. Então era essa a brincadeira completa, desaparecimento e reaparição, de que geralmente via-se apenas o primeiro ato, que era repetido incansavelmente como um jogo em si, embora sem dúvida o prazer maior estivesse no segundo ato. A interpretação do jogo foi simples, então. Ele estava relacionado à grande conquista cultural do menino, à renúncia instintual (renúncia à satisfação instintual) por ele realizada, ao permitir a ausência da mãe sem protestar." (FREUD, 2010, pp. 172-173)
} 
ferida simbólica que precisa ser compensada a posteriori. Como o inconsciente opera, segundo Freud, no eterno presente, o tempo de preparação que faltou antes acontece depois do trauma. O inconsciente dobra o passado e o transforma no futuro. Freud oferece como exemplo os sonhos que retornam o indivíduo ao momento traumático: "Tais sonhos buscam lidar retrospectivamente com o estímulo, mediante o desenvolvimento da angústia, cuja omissão tornara-se a causa da neurose traumática" (FREUD, 2010, p. 195). A elaboração da perda nos meses ou anos subsequentes ao acidente acontece de maneira similar a de quem acompanha um doente de câncer. Um acompanha a morte caminhando para ela de frente, o outro caminhando de costas, mas os dois em direção ao instante da perda. Aos poucos, o evento traumático é incorporado na complexa trama da vida e a energia desencadeada vai sendo amainada, pois "o processo de excitação se exaure no fenômeno de tornar-se consciente" (Ibidem, p. 186). Aos poucos, o indivíduo para de andar para trás.

Porém, a repetição compulsiva resiste a ser passada para a memória e, assim, a continuidade do tempo do presente para o passado fica comprometida. "Além da repetição que une, a repetição que apaga e destrói”'16 (DELEUZE, 1997b, p. 114). Freud observou este tipo de repetição especialmente "após sérias comoções mecânicas, desastres ferroviários e outros acidentes com risco de vida, ao qual se deu o nome de 'neurose traumática'” (FREUD, 2010, p. 168).

\begin{abstract}
As vítimas de trauma que Freud estudou também tinham sido tomadas pela surpresa, pois quando o choque Ihes "aconteceu" elas estavam despreparadas. A condição de terem "perdido" a ocorrência por não terem tido tempo para se proteger significou que o evento havia entrado profundamente nos alcances do inconsciente sem ter sido registrado conscientemente. Assim, eles também, num esforço para se prepararem finalmente para o evento, para testemunharem enfim o que teriam experimentado e perdido, estão fadados a repeti-lo e reviver a ansiedade de sua própria ausência paradoxal. (KRAUSS, 1997, p. 164) ${ }^{17}$
\end{abstract}

A continuidade seria característica de processos secundários, mas definitivamente não do inconsciente. Nossa habilidade de separar o que foi vivido do que está sendo vivido seria adquirida, segundo Freud, durante a elaboração dos processos

\footnotetext{
16 "beyond the repetition that links, the repetition that erases and destroys."

17 "The trauma victims Freud studied had too been taken by surprise, since their shock had 'happened' to them when they were unprepared. Their condition of thus having 'missed' the occurrence by not having had time to armor themselves against it meant that it had passed deeply into the inner reaches of their unconscious without having been registered consciously. Thus, they too, in an effort finally to prepare themselves for the event, so as to witness at last what they had both experienced and missed, are doomed to repeat it and relieve the anxiety of their own paradoxical absence."
} 
primários em secundários, e estaria intimamente ligada ao desenvolvimento da função de realidade. Segundo ele:

A tese de Kant, segundo a qual o tempo e o espaço são formas necessárias
de nosso pensamento, pode hoje ser submetida a uma discussão, devido
a certos conhecimentos psicanalíticos. Vimos que os processos psíquicos
inconscientes são "atemporais" em si. Isto significa, em primeiro lugar, que
não são ordenados temporalmente, que neles o tempo nada muda, que a
ideia do tempo não lhes pode ser aplicada. (FREUD, 2010, p. 190)

Freud afirma que "os processos que ocorrem nos sistemas inconscientes são fundamentalmente diversos daqueles dos (pré-)conscientes, que no inconsciente os investimentos podem ser transferidos, deslocados, condensados inteiramente" (Ibidem, p. 198). Ao que ele dá o nome de investimento, por conta de sua preocupação com as transações econômicas de energia psíquica, levo para o palco e dou o nome de imagens (se forem em pausa), texturas/frequências ou assemblages (se forem em movimento). Meu interesse se dá ao elaborar estratégias dramatúrgicas para que elas sejam alinhavadas de maneira similar à economia proposta por Freud para as operações dos investimentos no inconsciente, ou seja, por deslocamento, transferência e condensação.

A seguir, ele adiciona que "não é preciso muito para identificar o processo psíquico primário como o investimento livremente móvel” (Ibidem, p. 199), ou seja, profundamente não-causal e não-linear. Esta operação também me interessa muitíssimo, pois me permite vislumbrar uma dramaturgia livremente móvel na qual as imagens, texturas/frequências ou assemblages aparecem, desaparecem e reaparecem sem deixar pegadas. É como se elas ficassem à espera de irromperem novamente ou serem pescadas por outras, às vezes de formas transformadas mas ainda relacionadas aos conceitos que lhes fundamentam.

Acredito que entre todos os meus trabalhos, o que tenha explorado mais a fundo estratégias econômicas de transação no tempo-espaço seja (depois de) Antes da Queda (2010), concebido e dirigido por mim, e criado em parceria com as bailarinas Carolina Callegaro, Isabel Monteiro, Érica Tessarolo, Beatriz Sano e Maristela Estrela, esta substituída no meio do processo pela bailarina Flávia Scheye. Com trilha sonora especialmente composta por Jonas Tatit, figurinos de Paulo Babboni e desenho de luz de André Boll, esta peça foi o segundo trabalho da Companhia Perdida, e consistiu num aprofundamento do espetáculo Antes da Queda (2008). Ambas as peças foram inspiradas nas fotografias da artista americana Franscesca Woodman (1958-1981), que se fotografou incessantemente entre os 13 e 22 anos, até cometer suicídio ao se jogar de um edifício em Nova York. 
No inconsciente, a trajetória daquilo que desaparece num lugar e reaparece noutro não se mostra. Assim como ao piscarmos enquanto movendo a cabeça, não vemos como os objetos mudaram no espaço, vemos somente suas novas posições. A energia deslocada do inconsciente não deixa pegadas observáveis, porém as experiências deslocadas carregam uma certa singularidade que as une e permite que os sintomas desconexos sejam relacionados à mesma origem. "Repetição é atribuída a elementos que são realmente distintos porém dividem estritamente o mesmo conceito"18 (DELEUZE, 1997a, p.15).

No palco, ao invés de trabalhar com sintomas desconexos que têm o mesmo conceito, trabalho com cenas desconexas que têm o mesmo conceito, ou seja, elas mantém um traço de semelhança que faz com que as identifiquemos com uma origem comum. Por exemplo, a peça (depois de) Antes da Queda tem início com Érica cobrindo seus olhos com uma longa tira de papel kraft. O conceito de "cobrir os olhos" reaparece em vários outros momentos da peça, de formas diferentes. Primeiramente, ele reaparece na cena em que as cinco intérpretes sentam-se uma ao lado da outra, tampam seus olhos com faixas de papel e desenham nelas olhos falsos com pincel e tinta guache preta. Elas estão completamente cegas e não enxergam o que fazem mas, incrivelmente, os olhos desenhados carregam uma expressão fortíssima justamente pelos traços inseguros. A seguir, Carolina dança um solo inteiramente criado a partir dessa máscara, como se os olhos falsos adquirissem vida. Mais para frente, ela cobre o rosto de Isabel com um tecido cinza e as duas se beijam encarapuçadas. O mesmo capuz é depois transferido para o rosto da Érica, que termina a peça sentada nua com a face escondida. Numa outra cena Beatriz senta-se no chão e cobre o rosto com várias faixas com desenhos de olhos que foram se acumulando ao longo do processo de criação. Desta forma, Beatriz recupera o conceito de cobrir os olhos verdadeiros com olhos falsos, como se pescasse o tema que havia ficado suspenso no ar. Na última cena da peça, Bia esconde novamente seu rosto, desta vez com um espelho. Ou seja, o conceito de "cobrir os olhos" aparece de diferentes formas ao longo do trabalho, pois é feito com papel kraft, com tecido e com espelho, mas em todas as suas manifestações mantém-se a raiz do conceito que as fomenta.

O desenho dos olhos numa faixa de papel colocada sobre os de verdade traz à tona um outro conceito que reaparece ao longo da peça: o falso que se torna mais real do que o próprio real. $\mathrm{O}$ desenho dos olhos foi a primeira imagem que quis traba- 
Ihar com o elenco - fizemos disso um laboratório no primeiro dia de ensaios, ainda em 2008. A insegurança do traço e o fato de acompanharmos, como espectadores, a construção do desenho, tornam a cena extremamente interessante. Foi somente muito tempo depois, ao assistir ao belíssimo filme Valsa com Bashir (2008), no qual o cineasta israelense Ari Folman conta, através de desenho animado, o processo de reconstrução da sua memória na primeira guerra do Líbano, que compreendi o que ocorre com o desenho: através dele é possível dizer do que a realidade não é capaz. É preciso dar à realidade a possibilidade de existir como ficção para que consigamos ver alguns de seus precipícios - se a realidade os esconde, os desenhos os trazem à tona. Ao desenhar olhos cegamente sobre os olhos de verdade e mostrar o percurso do traço, as bailarinas expõem a si mesmas (ao ridículo, ao acaso, à melancolia) e também se mesclam com a angústia que imaginamos ter envolvido Francesca Woodman suicidar-se torna-se opção somente quando não se enxerga mais um caminho.

A relação entre o que é falso e o que é real entra em cena também na citação direta aos quadros de René Magritte Les amants I e II (1928), quando Isabel e Carolina se beijam com os rostos cobertos por tecido e depois se viram para o público num terno abraço: o beijo interditado nos faz não ter certeza se ele de fato pode ser considerado um beijo. A referência a Magritte não é à toa: num de seus quadros mais famosos, ceci n'est pas une pipe (1929), o artista pinta um cachimbo e sob ele enfatiza a falsidade da representação ao escrever que aquilo não é um cachimbo - da mesma forma como em (depois de) Antes da Queda desenham-se olhos que não são olhos e beijam-se beijos que não são beijos.

A estranheza que causa uma fricção na representação, quando o falso se faz notar por entre o real e vice-versa, também permeia toda a peça no que tange ao ambiente. Às vezes as bailarinas habitam espaços internos de uma casa, às vezes movem-se em meio à paisagem. Um espaço se metamorfoseia noutro através de uma mudança simples de luz ou da entrada de um novo objeto, que ressignifica toda a cena. Por exemplo, enquanto Beatriz move-se de olhos fechados com os braços de Isabel fingindo-se de seus (como na brincadeira infantil), Érica e Carolina levantam do chão bastões enormes de bambus (anteriormente camuflados) com os quais passam a se equilibrar numa lenta caminhada pelo espaço - os bambus fazem a cena ir para a paisagem ao ar livre. Em outro momento, um movimento de luz faz com que o tapete vermelho com flores se transforme numa relva florida iluminada pela lua cheia. Nos dois casos, tanto o bambu 
quanto a mudança da luz sobre o tapete fazem o espaço se metamorfosear de ambiente interno para externo, da contenção da casa para a liberdade ao ar livre. A única coisa real é o carpete; a paisagem é falsa, mas acreditamos nela.

4.

A narrativa criada pela repetição em movimento é sutil. Ela talvez não seja tão explícita quanto as narrativas verbais, porém ela pode criar complexidades através de estratégias estruturais que direcionam nossa percepção para alguns momentos chave ao invés de outros. A referência cruzada de tempo numa performance de dança é muito mais complexa do que sua duração pode sugerir. A troca entre presentes, passados e futuros através de antecipações, retenções, expectativas, previsões ou reapresentações desenrola uma teia de significados que não somente fundamentam a percepção do espectador sobre aquilo que está sendo visto, mas também permite a ele continuar os caminhos em sua imaginação.

Dança, teatro e performance em geral possuem uma certa duração à qual o espectador deve se adaptar. Assistir a uma performance (de dança, teatro, artes plásticas etc.) é uma experiência diferente da de ler um livro, pois o leitor decide o ritmo da leitura: ele pode reler passagens, descansar na cadeira e devanear sobre a história, inventar a fisionomia dos personagens, a arquitetura e a decoração da casa. No teatro, o estímulo é oferecido igualmente a todos os espectadores (obviamente o lugar do espectador no auditório modifica a percepção que ele tem da obra, mas não o ritmo da performance). Entretanto, o tempo cronológico de uma peça, seja de dança, teatro ou performance, só é percebido em sua medida quando não há engate entre a ação do palco e a atenção do espectador. Contamos os minutos quando o tédio nos toma, mas não quando uma peça nos interessa. Ao engatar na percepção, o tempo deixa de operar pelos minutos para se construir em outras medidas, que não cabem no relógio.

O fato da dança não possuir linguagem verbal para fundamentar entendimento e coerência não significa necessariamente que ela não seja capaz de desenvolver uma forma intrínseca de narrativa. Exatamente porque o espectador sentado no auditório não pode decidir sobre a velocidade da "leitura" e não pode "reler" passagens, o coreógrafo tem a opção de voltar no tempo para o espectador: o coreógrafo pode repetir passagens para assegurar o espectador de que as presenciou anteriormente e para construir novos significados a partir dessas reiterações. 
No movimento repetido, mesmo que de maneiras diferentes, o coreógrafo se assegura de que o movimento entra para a memória. Como Derrida escreveu: "o signo começa ao se repetir"19 (DERRIDA apud PHELAN, 1997, p. 8). Apesar de a dança não possuir linguagem verbal para estruturar coerência, ela pode gerar seus próprios significados através da repetição. "Porque a mente tem memória e adquire hábitos, ela é capaz de formar conceitos em geral e de abstrair algo novo, de subtrair algo novo da repetição que ela contempla"20 (DELEUZE, 1997a, p. 14). Quando um estímulo se repete, a conexão entre a primeira aparição e a segunda fecha o círculo necessário para a construção de significado, mesmo que este significado seja "expandido" e esteja em constante movimento. Diferentemente da palavra, o movimento ou a imagem de dança entram para a memória como bolhas suspensas à espera de encontros em pleno voo. Quando um signo-bolha se forma, ele é carregado por toda a peça sustentando a possibilidade de transformação por referências cruzadas e também por autonegações. Humberto Eco: "Daqui em diante serei incapaz de separar a referência conceitual do estímulo que a invocou e assim a surpresa desta união invariavelmente dará lugar ao complexo jogo da imaginação”21 (1989, p. 34).

\section{Referências bibliográficas}

Anais de Colóquio: Pina Bausch: falem-me de amor. Lisboa: Fenda Edições, 2006.

CANTON, Kátia. Eo príncipe dançou: o conto de fadas, da tradição oralà dança contemporânea. São Paulo: Editora Ática, 1994.

CYPRIANO, Fabio. Pina Bausch. São Paulo: Cosac Naif, 2005.

DELEUZE, Gilles. Difference and repetition. London: Athlone Press, 1997.

Coldness and Cruelty. In Masochism. New York: Zone Books, 1997.

ECO, Umberto. The open work. Cambridge, Massachusetts: Harvard University Press, 1989. FERNANDES, Ciane. O corpo em movimento: o sistema Laban/Bartenieff na formação e pesquisa em artes cênicas. São Paulo: Annablume, 2002.

Pina Bausch e o Wuppertal dança-teatro: repetição e transformação. São Paulo: Haucitec Editora, 2000.

FREUD, Sigmund. Além do princípio do prazer. In: Obras completas (1917-1920). São Paulo: Companhia das Letras, 2010. v.14.

Morning and melancholia. In: The standart edition of the complete psychological works of Sigmund Freud. Londres: The Hogarth Press, 1964, p. 237-258. v.XIV.

\footnotetext{
19 "The sign begins by repeating itself."

20 "because the mind has a memory and acquires habits, it is capable of forming concepts in general and of drawing something new, of subtracting something new from the repetition that it contemplates."

21 "from now on I will be unable to separate its conceptual reference from the stimulus that has invoked it, then the surprise of this union will invariably give way to the complex play of the imagination."
} 
The Uncanny. In: The standart edition of the complete psychological works of Sigmund Freud. Londres: The Hogarth Press, 1964, p. 217-252. v.XVII.

LAKOFF, George; JOHNSON, Mark. Metaphors we live by. London and Chicago: University of Chicago Press, 2003.

MLODINOW, Leonard. O andar do bêbado: como o acaso determina nossas vidas. Rio de Janeiro: Zahar, 2008.

PHELAN, Peggy. Mouring sex: performing public memories. London and New York: Routledge, 1997.

SERVOS, Norbert. Pina Bausch dance theatre. Munique: K• Kieser, 2008.

SERVOS, Norbert. Pina Bausch: Wuppetal dance theater, or the art of training a goldfish. Cologne: Verlag Koln, 1987.

SERVOS, Norbert. Pina Bausch: Dance and Emancipation. In: CARTER, Alexandra (org.) The Routledge dance studies reader. London and New York: Routledge, 1998.

SILVERMAN, Kaja. Male subjectivity at the margins. London and New York: Routledge, 1992. 